\title{
A migração mediterrânea e o mundo (neo)colonial na obra de Abdelmalek Sayad
}

\author{
Gustavo Dias*
}

AVALLONE, Gennaro; SANTAMARÍA, Enrique (org.). Abdelmalek Sayad: uma lectura crítica. Migraciones, saberes y luchas (sociales y culturales). Madrid: Dado Ediciones, 2018. (Disonancias, n. 5).

Em 2018, foram completados 20 anos da morte de Abdelmalek Sayad. Autor central nos estudos migratórios, Sayad deixou uma vasta produção bibliográfica dedicada, exclusivamente, ao drástico deslocamento populacional vivido pelas populações magrebinas, durante o brutal sistema colonial francês no norte da África. Todavia, seu legado interpretativo tem a capacidade de superar tal espacialidade e temporalidade e seguir atual enquanto uma sólida referência epistemológica para pesquisas migratórias em andamento. Isso, sobretudo, quando presenciamos, recentemente, uma intensificação dos processos de criminalização da migração e vulnerabilidade de sujeitos migrantes em diversos contextos fronteiriços.

Seu original legado interpretativo iniciou-se no final da década de 1950, quando, sob a supervisão de Pierre Bourdieu, um professor em início de carreira na Universidade de Argel, Sayad desenvolveu uma densa etnosociologia nas montanhas argelinas. Incursões por aldeias e zonas de reassentamentos forçados impostos pelo exército francês, uso de fotos, entrevistas e anotações de campo cuidadosamente debatidos no cair da noite

\footnotetext{
* Universidade Estadual de Montes Claros (Unimontes), Programa de Pós-graduação em Sociedade, Ambiente e Território - UFMG/Unimontes, Montes Claros-MG, Brasil (tentonidias@hotmail.com; https://orcid.org/0000-0001-5325-3253).
} 
- quando o patrulhamento colonial se tornava mais fácil de ser burlado - possibilitaram uma compreensão sistêmica das transformações socioculturais vivenciadas pelas populações magrebinas sob a ocupação francesa (PÉREZ, 2017). A partir de um comprometimento com a pesquisa de campo, Sayad continuaria, já em Paris, até o final de sua breve vida, dedicado à compreensão da migração mediterrânea enquanto uma dinâmica populacional intimamente atrelada ao impacto da imposição do sistema capitalista sobre as comunidades tradicionais magrebinas e seus modos de vida.

No Brasil, seus trabalhos são referências para o campo dos estudos migratórios tanto nacionais quanto internacionais. Não por acaso, Sayad esteve por duas vezes no Brasil, durante a década de 1990. "A intensificação da cooperação científica entre o Museu Nacional e o CSE nos anos 80 permitiu as duas estadias de Sayad no Brasil, em 1990 e em 1994" (GARCIA JR., 2018, p. 64). Incursões a campo, com pesquisadores brasileiros, no Rio de Janeiro, São Paulo e no Nordeste, seminários, entrevista ${ }^{1}$ e um $\operatorname{artigo}^{2}$ deixaram uma importante contribuição inicial da divulgação de seu trabalho por aqui. Em 1998, a Edusp editou seu clássico livro A imigração ou os paradoxos da alteridade e, postumamente em 2000, a revista Travessia publicou seu texto "O retorno: elemento constitutivo da condição do imigrante”. Contudo, todas essas publicações encontram-se esgotadas e, até o momento, sem previsão de republicação. Assim, apesar de bastante conhecido e citado no campo dos estudos migratórios, desenvolvido no Brasil, contraditoriamente, a produção intelectual de Abdelmalek Sayad é de difícil acesso na academia brasileira, sobretudo, entre os pesquisadores envolvidos nos primeiros passos da iniciação científica ou até matriculados em programas de pós-graduação (DIAS, 2019).

Em virtude das homenagens dos 20 anos da morte de Abdelmalek Sayad, presenciamos algumas produções acadêmicas em diversos locais do globo. ${ }^{3} 0$ livro Abdelmalek Sayad: uma lectura crítica. Migraciones, saberes y luchas (sociales y culturales), coordenado pelos sociólogos especialistas em estudos migratórios, Gennaro Avallone e Enrique Santamaría, e publicado pela editora espanhola Dados Ediciones, faz parte desse importante ciclo de homenagens.

Trata-se de uma coletânea de textos - 18 no total -, dividida em cinco partes, redigidos por pesquisadores que têm desenvolvido trabalhos à luz do pensamento de Abdelmalek Sayad em diversos centros de pesquisa localizados no sul e norte global. 0 livro propõe-se a analisar, criticamente, as contribuições de Sayad para a compreensão das migrações. Em alguns trabalhos, suas reflexões são aplicadas em estudos de casos contemporâneos. A primeira parte explora a própria condição migratória vivida por Sayad e como essa

\footnotetext{
1 “Colonialismo e migrações”, entrevista concedida à revista Mana: Estudos de Antropologia Social, publicada em 1996.

2 “Uma pobreza 'exótica': a imigração argelina na França”, artigo publicado pela Revista Brasileira de Ciências Sociais, em 1991.

${ }^{3}$ Em Paris, ocorreu o evento Retours sur les travaux et la pensée d'Abdelmalek Sayad, no EHESS, entre dias 27 e 28 de setembro de 2018. No Brasil, tivemos o seminário 20 anos depois: a contemporaneidade do pensamento de Abdelmalek Sayad, na PUC-SP, entre 2 e 4 de outubro de 2018. E, em Córdoba, ocorreu o ciclo de palestras Migrar como subversión: un homenaje a Abdelmalek Sayad, de 16 a 23 de novembro e 7 de dezembro de 2018, na Universidad Nacional de Córdoba.
} 
experiência transparece em sua obra. A segunda traz ricas e, talvez, inéditas interpretações para o público brasileiro; aqui, os autores discutem, primeiramente, as contribuições do sociólogo argelino à luz de perspectivas pós-coloniais e, de maneira mais geral, a compreensão do fenômeno migratório do ponto de vista metodológico e epistemológico. Já a terceira parte reúne artigos que exploram a trajetória migratória por meio do mercado de trabalho, habitação e seus significados simbólicos na vida cotidiana. A quarta parte é dedicada ao Estado, suas políticas migratórias e a produção de fronteiras. Por fim, a quinta e última parte oferece um olhar sobre as experiências de expropriação - a história colonial da Argélia, o islamismo na França e a memória - que Sayad estudou a partir da migração.

Essa resenha não pretende esmiuçar capítulo por capítulo. Diante do limite de espaço, torna-se interessante analisar, com um pouco mais de cuidado, alguns pontos trabalhados no livro. Assim, elegem-se as categorias Estado, migrante e, por fim, história, que são trabaIhadas por diversos autores aqui reunidos e, portanto, volta e meia, emergem ao longo de todo o livro. Talvez essa seja uma das importantes contribuições dadas pelo livro àqueles que querem conhecer o legado epistemológico de Sayad ou entender sua potencialidade para pensar deslocamentos populacionais atuais.

Entretanto, abre-se uma exceção para a primeira parte, “Abdelmalek Sayad: vida y obra". Como mencionado anteriormente, o livro contém textos que analisam a vida e a obra do sociólogo argelino. E ele tem sucesso em sua proposta. Nesse ponto, assemelha-se bastante aos ricos trabalhos desenvolvidos por Yacine Tassadit, Yves Jammes e Christian de Montlibert (2013) e Miles Reding (2017), que, respectivamente, exploram a trajetória intelectual de Sayad na Argélia e França. Os textos de Danielle Provansal (2018), Hadj Belgavem e Fari Taalba (2018) e Esteban Mate (2018) compõem essa primeira parte. Em suma, os trabalhos defendem a necessidade de entendermos como as reflexões desenvolvidas por Sayad guardam origens em sua trajetória pessoal no sistema colonial francês na Argélia e seus desdobramentos após a guerra da independência.

Ao longo dos três capítulos, podemos acompanhar, de forma breve, o desenvolvimento da vida de Malek Ath Messaoud. ${ }^{4}$ Vamos, portanto, desde a sua infância, na aldeia de Aghbala, na pequena Cabília, onde Belgavem e Taalba demonstram o esforço dos pais para assegurar a ele, único filho homem, a educação escolar. Acompanhamos as constantes migrações ou fugas que ele e sua família vivenciaram em decorrência das represálias políticas vividas pelo pai, que sempre manteve um posicionamento progressista perante famílias poderosas locais. Concluído o liceu, Sayad iniciou a carreira como professor escolar e filiou-se à Union Générale des Travailleurs Algériens (UGTA) e à Front des Forces Socialistes (FFS).

Entre 1958 e 1961, Sayad começou seus estudos na Universidade de Argel e teve decisiva participação na pesquisa, conduzida por Pierre Bourdieu, que culminaria no clássico

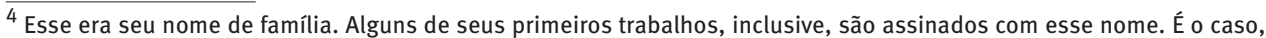
por exemplo, do trabalho L'immigration Algérienne en France, publicado em coautoria com Alain Ginette, em 1974. Apenas mais tarde adotaria em definitivo seu nome civil, Abdelmalek Sayad.
} 
Le déracinement. La crise de l'agriculture traditionnelle en Algérie, publicado em 1964. "Ele era argelino, originário da Cabília, falava amazigh e também falava árabe. Portanto, ele era a pessoa certa para introduzir a meios de difícil acesso um jovem pesquisador francês" (PROVANSAL, 2018, p. 12, tradução nossa). Como pano de fundo, ao longo de todo o livro, vislumbramos uma Argélia que sofre dura repressão do sistema colonial francês desde o século XIX. Destruição de vilas e suprimentos, deslocamentos forçados, campos de reagrupamento populacional monitorados pelo exército francês e, ainda, a presença constante da violenta Organisation Armée Secrète (OAS), grupo paramilitar francês, compõem o ambiente social no qual o sociólogo cresceu.

Em 1963, Sayad mudou-se para a França. Não é exagero dizer que, a partir de sua vida em solo francês, retratada nesse livro, presenciaremos a comprovação da teoria bourdiesiana acerca da disputa do campo científico (1983). Magrebino, migrante, com uma formação escolar e universitária na Argélia e pesquisador de um tema marginal, ${ }^{5}$ ele custaria a conseguir seu espaço na academia francesa. Mesmo com o apoio de Pierre Bourdieu e Claude Lévis-Strauss, sua candidatura formal ao Centre National de Recherche Scientifique (CNRS) foi recusada de início. Apenas em 1977 foi integrado, definitivamente, com um projeto de pesquisa dedicado à imigração argelina, tema que revelava uma constante preocupação do governo francês com a intensa presença de magrebinos em seu território.

Nessa tônica, Abdelmalek Sayad: uma lectura crítica explora, com o devido cuidado, o papel do Estado nos estudos de Sayad. Segundo o livro, para Sayad, os Estados francês e argelino estariam, de forma contínua, presentes na produção e reprodução do fenômeno migratório. 0 sistema colonial francês foi, inicialmente, responsável pelo desenraizamento da população campesina do universo rural argelino. Como elucida Luana Colella (2018, p. 192, tradução nossa), na terceira parte do livro,

[...] a França colonialista irrompeu violentamente no mundo camponês argelino, privando os nativos de sua única fonte de subsistência - o terreno para o cultivo - gerando inevitavelmente seu empobrecimento e, em consequência, assumindo o sentimento cínico de ter sido afetado, para sempre, o senso comum de pertencer a uma identidade comunitária, tão menos valorizada pela lógica da modernidade capitalista.

Contudo, o final da colonização francesa, em 1962, não necessariamente findaria com o brutal processo de desenraizamento. 0 Estado argelino teria herdado tal política da morte. E, aqui, Fabio Raimondi ressalta a contribuição de Sayad para pensarmos o papel do Estado em sociedades independentes, mas não emancipadas dos grandes centros europeus.

\footnotetext{
${ }^{5}$ Cabe destacar que, até a primeira metade do século XX, a academia francófona apresentava séria resistência ao surgimento de um campo de estudo específico sobre o fenômeno migratório, mesmo que houvesse um interesse político e midiático para "o problema da imigração". "Diversas perspectivas teóricas foram utilizadas para explicar esse fato: a divisão do trabalho científico (o estudo da imigração era uma tradição estabelecida na demografia e na geografia humana), o legado da escola durkheimiana (que não estava interessada no estudo das migrações, com exceção de Maurice Halbwachs), o peso da análise marxista (que favoreceu, em primeiro lugar, a análise através de classes sociais e 'o exército de reserva'), as representações coletivas da sociedade francesa (em particular aquelas relacionados à memória colonial)" (MOHAMMEDI, 2014, p. 8, tradução nossa). Porém, o estudo da migração seguiu preterido no campo científico, porque o seu objeto de estudo, a pessoa do migrante, era marginal. Seria, contudo, com Abdelmalek Sayad, em meados dos anos 1970, que a academia francesa passaria lentamente a trazer contribuições originais para o estudo migratório.
} 
Se, para Weber, o Estado é o exercício legítimo da força física (poder) dentro de um território definido e em uma população definida em si, à qual Bourdieu acrescenta a especificação de que esse poder também é simbólico, para Sayad, o Estado é configurado acima de tudo como um poder, não necessariamente legítimo, de expulsão. (RAIMONDI, 2018, p. 264, tradução nossa)

Nota-se que se trata de uma leitura bastante refinada e distinta das estabelecidas na academia europeia. 0 Estado argelino, em prol de uma modernidade, seguiria enxotando sua população do campo. Despossuídos do ethos campesino, levas de trabalhadores formam, agora, uma espécie de subproletariado desqualificado, barato e descartável para a economia francesa. Em outras palavras, isenta-se de qualquer responsabilidade sobre a vida de cidadãos lançados à sorte na travessia do mediterrâneo. Estados argelino e francês trabalham, conjuntamente, na capacidade de ditar a forma de morrer desses despossuídos da terra: o exílio. Temos, aqui, já na década de 1960, um autor pós-colonial pensando a necropolítica enquanto maneira de governar. Já em solo europeu, o Estado francês e suas severas fronteiras burocráticas definem esses magrebinos enquanto trabalhadores temporários que estão na França de forma provisória. Nas palavras de Amín Pérez (2018, p. 243, tradução nossa), trata-se de "corpos estatizados que incorporam e produzem esta condição imigrante, legitimada somente por sua dimensão temporal, econômica e apolítica”. Para Sayad, o fenômeno imigratório teria a capacidade de desconstruir "a ilusão coletiva sobre a qual se baseia a própria justificativa da existência do Estado, constituindo, assim, um desafio às suas estruturas” (GERBEAU, 2018, p. 281, tradução nossa).

Abdelmalek Sayad: uma lectura crítica tece, cuidadosamente, a leitura focada na dinâmica macro do Estado com a perspectiva micro dos agentes sociais. Sem a ilusão coletiva de pertencimento a um território, nos deparamos, agora, com o sujeito migrante, trabalhado com maior precisão na terceira parte, a qual demonstra como Sayad interpretava a emigração e imigração magrebinas enquanto partes de um único processo. A leitura do texto de Elena Gadea e Andrés Pedreño (2018), seguida de Andrés Davila Legerén (2018), revela tal êxito nesse exercício. Estados argelino e francês, ao lado dos próprios migrantes, produzem a ilusão da provisoriedade. Sujeitos destituídos de vida política sobrevivem a duras penas, exilados nas duas margens do Mediterrâneo. Na Argélia, foram expulsos do campo e passam a viver uma infindável ilusão de que retornarão um dia. Já na França, são relembrados, diariamente, que suas permanências dependem de um trabalho. Muitos vivem confinados nas miseráveis bindovilles, precárias habitações que se encontram, metaforicamente, distantes da própria França.

Preso naquele território paradoxal, que existe, mas não existe de todo, que não existe, mas sem deixar de existir, esses trabalhadores argelinos e suas famílias se esforçam para fazer que na bidonville seja possível a "vida apesar de tudo", para que "se tenha tornado em um mundo autêntico, um cosmos que se inclina para a autonomia quase absoluto. Assim, a bidonville, espaço de rebaixamento, desempenhará o papel de um espaço de refúgio" (ibid.: 76). E assim o território paradoxal se revela uma rede de espaços paratópicos. (LEGERÉN, 2018, p. 226, tradução nossa) 
O sujeito migrante é alguém deslocado em sua totalidade. Em outras palavras, é um não-ser que convive com a dupla ausência de um lar político.

A partir da leitura do livro, pode-se concluir que Sayad deixou - para além de suas contribuições conceituais e metodológicas - um outro considerável legado para o campo dos estudos migratórios: o uso da sociologia histórica. Crítico à postura do Estado francês, que entende a migração enquanto um "problema social" e, portanto, demandando rápida solução, Sayad demonstra que a migração magrebina não é exclusivamente "factual”, mas também produto de um longo processo histórico, diretamente atrelado aos mais de cem anos de ocupação francesa (BRAUDEL, 2005). Por meio de Pierre Bourdieu, Sayad assimila a importância da historiografia para a sociologia. 0 uso da sociologia histórica remonta suas origens em figuras centrais no desenvolvimento da própria sociologia na França: presente já nos estudos iniciais de Émile Durkheim, passou por Maurice Halbwachs, fervoroso devoto e membro da primeira geração dos Annales, seguiu com Georges Gurvitch, sociólogo russo erradicado na França e que trabalhou com Fernand Braudel, e somou a figura do competente Pierre Bourdieu (STEINMETZ, 2011). Como dito no início dessa resenha, Sayad desenvolveu, desde o começo de sua carreira de pesquisador, uma etnosociologia que - contrária ao estruturalismo de Claude Lévis-Strauss - analisava a população cabila enquanto uma cultura histórica, que vinha tendo seu habitus remodelado por longos períodos de contato com conquistadores árabes e franceses. A migração, portanto, é fruto desse longo processo histórico. Não à toa, Sayad publicou, entre 1975 e 1999, uma dezena de textos nas Actes de la Recherché en Sciences Sociales, periódico fundado por Pierre Bourdieu, em 1975, e dedicado ao estabelecimento de uma unidade entre a sociologia e a história.

Tal unidade, presente na obra de Sayad, aparece em todas as cinco partes de Abdelmalek Sayad: uma lectura crítica. Destaca-se, em particular, o texto de Cecilia Jiménez Zunino. A autora argumenta que compreender os legados coloniais e neocoloniais, na obra de Sayad, é fundamental para entendermos o deslocamento populacional para além das teorias econômicas neoclássicas centradas no modelo push-pull, que ainda povoam os estudos migratórios. “Assim, seriam observados não apenas indicadores econômicos para determinar a orientação dos fluxos migratórios, mas também o processo de conformação sócio-histórica das trocas entre países, entre os quais figura a população" (ZUNINO, 2018, p. 76, tradução nossa). Em suma, Abdelmalek Sayad: uma lectura crítica apresenta-nos esse sociólogo das migrações enquanto um pensador argelino do pós-Segunda Guerra Mundial e que questionou severamente as misérias produzidas e mantidas pelo capitalismo nas periferias do mundo.

\section{Referências}

BELGAVEM, H.; TAALBA, F. La Argelia de Abdelmalek Sayad. Génesis de um sociólogo en el contexto colonial. In: AVALLONE, G.; SANTAMARÍA, E. (org.). Abdelmalek Sayad: uma lectura crítica. Migraciones, saberes y luchas (sociales y culturales). Madrid: Dado Ediciones, 2018. (Disonancias, n. 5). 
BOURDIEU, P. O campo científico. In: ORTIZ, R. (org.). Pierre Bourdieu: sociologia. São Paulo: Ática, 1983. p. 122-155.

BOURDIEU, P. Um analista do inconsciente. In: SAYAD, A. A imigração ou os paradoxos da alteridade. São Paulo: Edusp, 1998. p. 9-12.

BRAUDEL, F. Escritos sobre a História. São Paulo: Perspectiva, 2005.

COLELLA, E. Abdelmalek Sayad: para una sociología postcolonial de la emigración-inmigración ante litteram. In: AVALLONE, G.; SANTAMARÍA, E. (org.). Abdelmalek Sayad: uma lectura crítica. Migraciones, saberes y luchas (sociales y culturales). Madrid: Dado Ediciones, 2018. (Disonancias, n. 5).

DIAS, G. As origens de uma etnosociologia combativa nas fronteiras coloniais. Revista TOMO, v. 35, n. 1, p. 317-326, 2019.

GADEA, E.; PEDREÑO, A. Descampesinización, expulsión y migraciones internacionales: Sayad y el estudio de las migraciones rurales. In: AVALLONE, G.; SANTAMARÍA, E. (org.). Abdelmalek Sayad: uma lectura crítica. Migraciones, saberes y luchas (sociales y culturales). Madrid: Dado Ediciones, 2018. (Disonancias, n. 5).

GARCIA JR., A. Abdelmalek Sayad no Brasil: os imigrantes internacionais como um caso limite de agentes sociais forçados à reconversão. Contemporânea, v. 8, n. 1, p. 59-83, 2018.

GERBEAU, Y. M. Programas de migración temporal ¿la utopía del pensamiento de Estado hecha realidad? In: AVALLONE, G.; SANTAMARÍA, E. (org.). Abdelmalek Sayad: uma lectura crítica. Migraciones, saberes y luchas (sociales y culturales). Madrid: Dado Ediciones, 2018. (Disonancias, n. 5).

LEGERÉN, A. D. Abdelmalek en el Pa(r)ís de las chabolas. A propósito de Un Nanterre algérien, terre de bidonvilles y el interés socio-discursivo de Sayad. In: AVALLONE, G.; SANTAMARÍA, E. (org.). Abdelmalek Sayad: uma lectura crítica. Migraciones, saberes y luchas (sociales y culturales). Madrid: Dado Ediciones, 2018. (Disonancias, n. 5).

MATE, E. De la (ir)elevancia espitémica de las migraciones. A propósito de la edición de $L a$ doble ausencia de A. Sayad. In: AVALLONE, G.; SANTAMARÍA, E. (org.). Abdelmalek Sayad: uma lectura crítica. Migraciones, saberes y luchas (sociales y culturales). Madrid: Dado Ediciones, 2018. (Disonancias, n. 5).

MOHAMMEDI, S. M. (org.). Abdelmalek Sayad, migrations et mondialisation. Oran: Éditions Crasc, 2014.

PÉREZ, A. La liberación del conocimiento. Bourdieu y Sayad frente al colonialismo. In: BOURDIEU, P.; SAYAD, A. El desarraigo: la violencia del capitalismo en una sociedad rural. Buenos Aires: Siglo Veintiuno Editores, 2017.

PÉREZ, A. La producción cultural de las fronteras. La cuestión migratoria en el pensamiento de Estado. In: AVALLONE, G.; SANTAMARÍA, E. (org.). Abdelmalek Sayad: uma lectura crítica. Migraciones, saberes y luchas (sociales y culturales). Madrid: Dado Ediciones, 2018. (Disonancias, n. 5).

PROVANSAL, D. Abdelmalek Sayad o el doble exilio. In: AVALLONE, G.; SANTAMARÍA, E. (org.). Abdelmalek Sayad: uma lectura crítica. Migraciones, saberes y luchas (sociales y culturales). Madrid: Dado Ediciones, 2018. (Disonancias, n. 5).

RAIMONDI, F. Los migrantes y la contradicción entre capital y Estado. Para una confrontación entre Sayad y el marxismo. In: AVALLONE, G.; SANTAMARÍA, E. (org.). Abdelmalek Sayad: uma lectura crítica. Migraciones, saberes y luchas (sociales y culturales). Madrid: Dado Ediciones, 2018. (Disonancias, n. 5). 
REDING, M. "Yesterday's colonization and today's immigration": an intellectual biography of Abdelmalek Sayad, 1957-1998. Thesis (Masters in Arts) - University of Oregon, 2017.

STEINMETZ, G. Bourdieu, historicity, and historical sociology. Cultural Sociology, v. 5, n. 1, p. 45-66, 2011.

TASSADIT, Y.; JAMMES, Y.; DE MONTLIBERT, C. Abdelmalek Sayad, la découverte de la sociologie en temps de guerre. Nantes: Éditions Cécile Defaut, 2013.

ZUNINO, C. J. Sayad en uso: trayectorias y proyectos migratorios como herramientas de análisis. In: AVALLONE, G.; SANTAMARÍA, E. (org.). Abdelmalek Sayad: uma lectura crítica. Migraciones, saberes y luchas (sociales y culturales). Madrid: Dado Ediciones, 2018. (Disonancias, n. 5).

\section{Sobre o autor}

Gustavo Dias é PhD em Sociologia pela Goldsmiths College/University of London (Inglaterra). Professor do Departamento de Ciências Sociais da Universidade Estadual de Montes Claros (Unimontes) e do Programa de Pós-graduação em Sociedade, Ambiente e Território (UFMG/ Unimontes).

\section{Endereço para correspondência}

Campus Universitário Prof. Darcy Ribeiro, prédio 7, sala 202

Av. Prof. Rui Braga, s/n, Vila Mauriceia

39401-089 - Montes Claros-MG, Brasil

Recebido para publicação em 26/02/2020

Aceito para publicação em 11/05/2020 